\section{New Trends and Issues Proceedings on Humanities and Social Sciences}

Volume 6, Issue 3 (2019) 095-101
'New Trends and Issues Proceedings on Humanities and Social Sciences

www.prosoc.eu

Selected Paper of 8th World Conference on Business, Economics and Management (BEM-2019) 26 - 28 April 2019, Grand Park Lara Hotel Convention Center, Antalya, Turkey

\title{
Social economy in the international scenery: Politic(s), culture(s) and power(s)/pressure(s) manipulation
}

Ana Campina*, Universidade Portucalense \& Instituto Juridico Portucalense, Rua Dr. Antonio Bernardino de Almeida, 541, 4200-072 Porto, Portugal

Maria Manuela Magalhaes Silva, Universidade Portucalense \& Instituto Juridico Portucalense, Rua Dr. Antonio Bernardino de Almeida, 541, 4200-072 Porto, Portugal

\section{Suggested Citation:}

Campina, A. \& Silva- Magalhaes, M.M. (2019). Social economy in the international scenery: politic(s), culture(s) and power(s)/pressure(s) manipulation. New Trends and Issues Proceedings on Humanities and Social Sciences. [Online]. 6(3), pp 095-101. Available from: www.prosoc.eu

Selection and peer review under responsibility of Prof.Dr. Cetin Bektas, Gaziosmanpasa University, Turkey. C2019 United World Center of Research Innovation and Publication. All rights reserved.

\begin{abstract}
We live a dangerous world 'scenery' due to ideas and ideologies manipulation/proliferation, the inherent social perceptions and the consequently tampered behaviours engaged in violence. If the Humanity is a complex context, States, Governments, politic, politics, societies, cultures, religions, ideological groups (social, ethnic, legal, illegal, declared and unknown), the Media all have a powerful action being important 'actors' which actions should be careful and critically studied. The manipulation is a riskily reality being disproportionate developed with the worst consequences. Discourses are the easiest instrument to analyse, with insidious messages, considered 'normal' but being a simple manipulated information generating tampered and seriously dangerous violent actions is the question of the Religions and the Terrorism. It is urgent to invest in the equality and 'construct' the respect for all religions, cultures, especially promote the education for the different thinking, way of living and face the realities.
\end{abstract}

Keywords: Human rights, social, policies, oppositions.

\footnotetext{
* ADDRESS FOR CORRESPONDENCE: Ana Campina, Universidade Portucalense \& Instituto Juridico Portucalense, Rua Dr. Antonio Bernardino de Almeida, 541, 4200-072 Porto, Portugal. E-mail address: acampina@upt.pt / Tel.: +351-225-572-000
} 
Campina, A. \& Silva- Magalhaes, M.M. (2019). Social economy in the international scenery: politic(s), culture(s) and power(s)/pressure(s) manipulation. New Trends and Issues Proceedings on Humanities and Social Sciences. [Online]. 6(3), pp 095-101. Available from: www.prosoc.eu

\section{Introduction}

Nowadays, social economy in the international scenery is a challenge as the Organisation for Economic Co-operation and Development (OECD) presents: 'the social innovation seeks new answers to social and societal challenges for instance by identifying and delivering new services that improve the quality of life of individuals and communities or new labour market integration processes, new competencies, new jobs and new forms of participation and inclusion' (OECD, 2019). However, there are dangerous political, culture and power(s) pressure and manipulation, due to the serious consequences for the human beings, states and the legal and judicial international protection of the Human Rights-'Wherever social innovations appear, they bring about new processes or organisational changes or changes in financing, along with more collaborative dynamics among the stakeholders, including citizens, to design and implement innovative solutions'. (OECD Social Economy, 2019)-Due to the 'potential growth is expected to decelerate in advanced economies, partly due to demographic factors. This deceleration is likely to be more severe if government policies lead to heightened restrictions on immigration, as immigrants tend to be younger than the native population' (WB Flagship Report, 2019, p. 39).

Although the importance of the economies within the individual States-Nation, and almost all political actions, are developed in this level, as the globalisation is a growing force that all affects, since the levels of the incomings, the employment perspectives and dimension of our knowledge and information (Milanovic, 2016, p. 13).

\section{Social economy in the international scenery and the Human Rights: the research and the interpretation}

The 21st century has promoted a complex and controversial paradigm shift in Human Rights for a variety of reasons: terrorist attacks and consequent maximum security measures; the expanding antiSemitic ideologist; racism and discrimination whose statistics show that they are at a dangerous level; the 'new' Refugee crisis; the economic crisis that has led millions to effective poverty; the lack of capacity of the Public Opinion to interpret and (re) act in accordance with the real needs (fragile and/or manipulated information); the distance between theory and practice that support Rights violations.

Considering the evidence of Human Rights Education policies in the European Union as a procedure/obligation and the political strategy, it should be a top priority in structural political programmes in the cultural, religious, economic and financial context, but it has revealed gaps that have seriously affected citizenship in the EU.

This research confirms that the 'Crisis' of Refugees in the European Union, whose real dimension we cannot identify at present, should deserve attention and specific work. It is unquestionable that this 'crisis' began during World War II, having survived to the present day in the most diverse and complex situations within the EU, with very serious effects, also on a world scale, as regard the violation of human rights. Human Rights and Fundamental Rights of the European Union and European states. Xenophobia, racism and discrimination are problems with refugees from the most 'discreet' actions to the serious consequences that the EU faces, without the necessary control, which should be interpreted on the basis of philosophy and legality, and/or violation of Human rights in a contextual understanding of widespread social humanitarian behaviour.

According to the diagnosed needs, political rhetoric is not sufficient for the change of the Public Opinion, but it is a crucial starting point for the promotion of a global and Human vision under the recontextualisation of the contexts and events, pedagogically controlled by the re-education for 'new' perceptions, 'positions' that generate behaviours-social and individual-away from the controversy and the negative complexity of opposition. 
Campina, A. \& Silva- Magalhaes, M.M. (2019). Social economy in the international scenery: politic(s), culture(s) and power(s)/pressure(s) manipulation. New Trends and Issues Proceedings on Humanities and Social Sciences. [Online]. 6(3), pp 095-101. Available from: www.prosoc.eu

Thus, in fact, there are Human Rights Education policies at different scales-international, regional and national (of the member states of the European Union), but these realities allow us to affirm an unavoidable reality: the dichotomy of legal procedures and effective social needs. There is, therefore, a need for concerted action aimed at an effective EU development that identifies a whole range of interests and lobbies that have a very negative and dangerous effect on these human beings who are forced to seek refuge, but who face a whole situation that should be protection and solution (support), but complicated by bureaucracies, manipulations and obstacles that aggravate their human and family situation. Member States, EU institutions, the UN and civil society should organise themselves seriously in order to denounce all violations, characterise the realities and the obstacles and means involved and necessary; European and international legal and judicial action, in a joint action that promotes an effective Human Rights Education programme to achieve effective results.

All these issues are duly legally protected by documents within the United Nations System, the Universal Declaration of Human Rights of 1945, the subsequent Covenants, and the consequent International Agreements and Treaties governing Relations between States, the diagnosis of violence and of the violation and, of course, of the consequent international legal action. With regard to the $\mathrm{EU}$, in addition to the democratic values that are at the heart of the EU, the Treaties, which legally regulate its operation and the 'bigger' legal document in this context: the Charter of Fundamental Rights of the European Union (Rocha, 2010 Campina, 2017).

\section{Research results discussion}

With this research we can state that 'the policies needed to reduce inequality are clear, including the provision of universal public services and social protection, paid for by the taxation of the richest people and corporations' (Oxfam Report, 2019, p. 72). So, we have to understand the problems that world face nowadays, having in mind the solution has to be supported in the economic policies avoiding the 'powers' pressures, the manipulation(s) and the cultures complexity.

Today, in the world and in Humanity, from the West to the East, the present research and study of Human Rights, considering the differences, the complex contexts and their variables, is a central and urgent question that demands: to be scientifically reflected; legally adjusted; culturally interpreted; political priority in line with the policies in force within the international, regional and national strategies and actions, object of a structured education for a citizenship aware of the reality (s) and the most distinct (and potential) manipulations.

From a historical perspective, human rights issues are seriously 'contaminated' by complexity and 'misrepresentation' of concepts and definitions, especially due to the gaps in the studies and the consequent dichotomy between legality and effective social needs. Consequently, due to the lack of a strategic international development strategy and a true diagnosis, there is a need for the structuring and implementation of a system of education, protection and promotion of human rights, a little around the world in accordance with the needs of each situation (state).

If the United Nations system is fully operational at the international level, in matters of international affairs and relations, this issue should be a permanent priority. In spite of some developed legal procedures, actions and programmes that are developed and implemented based on Human Rights Education, aiming at supporting and protecting millions of people, who effectively face the most different violations and violations of their rights, in the most diverse areas of their lives, which would help to solve a panoply of problems and generate (re)new behaviours and actions supported by their needs, facing the problems to solve them, or at least to mitigate them, by facing the difficult problems and/or human/social crises. However, there is no effective concerted project to reach as many (possible) people as possible in their real needs. Thus, in this context, Contemporary History has failed to implement a Human Rights Education, which has contributed to the proliferation of problems in the most different areas, individual and social, in the most diverse areas worldwide. 
Campina, A. \& Silva- Magalhaes, M.M. (2019). Social economy in the international scenery: politic(s), culture(s) and power(s)/pressure(s) manipulation. New Trends and Issues Proceedings on Humanities and Social Sciences. [Online]. 6(3), pp 095-101. Available from: www.prosoc.eu

The paradox is that human rights are now being evoked as they have never been in the past, but in contrast, there is a panoply of very dangerous human actions with the most serious consequences: information is recurrently released without the necessary contextualisation based on facts and legal procedures, as well as explanations adapted to the target public (individual or group/social) in the most different and complex realities. Thus, Human Rights in the Agenda of democratic states, as a priority in the Media, in social discussions (official and unofficial), in countries, regional groups/Organisations, International Organisations (governmental or otherwise) as objectives and actions. But in the discourse of terrorist groups, as 'flag' in the plane of their actions of 'recruiting' followers in the name of some values completely distorted within the worst objectives. This problem affects states with undemocratic, mostly authoritarian regimes, where there are fundamental rights in their national legislation, in their rhetoric, despite the most effective condemnation of human rights violations.

In this regard, considering the possibility of legally determining Human Rights in the United Nations system, starting with the Universal Declaration of Human Rights of December 10, 1948 (for all Human Beings in the world), as well as all legal documents international organisations of the same system, recognised and adopted by UN members. However, fundamental rights are regarded as those which are legally recognised in each state or regional organisation or system, such as the European Union.

It is unquestionable that International Relations and Policies, where democracy is the basis, there is the development and support of Human Rights with its values that form discourses, such as actions that generate behaviours. And, despite all the adversities and problems, in a world-wide perspective, it is possible to affirm that, in the majority, no more laws are needed, but their effective implementation, which means that the existence of legal instruments of Human Rights and judicial, the consequent procedures, aiming to live within the law, judicial control of all violations and inherent punishments of all (people, states or institutions) that do not follow the legal regulations.

However, it is unquestionable that many states/governments need to recognise and adopt-with the greatest urgency and brevity-in their legislation Human Rights, democratising their policies aiming at strategies to protect citizens from violence, violations and suffering in the most different dimensions of one's life. Concerning the democratic states that protect and promote these rights (globally), there is a whole challenge of social renewal and construction of reflection on the criteria of social, economic and cultural policy in actions that effectively implement democratisation through realistic and honest plans, avoiding the problems that have already been identified and known, before/anticipate possible problems, through a serious diagnosis, identifying and characterising all the 'actors' in the societal and political scenario, acting to proceed with a qualified Democracy of all for all, the citizens.

This is a realistic and scientific perception that is defended by Laurence Whithead (Laurence WHITEHEAD, University of Oxford, Senior Research Fellow in Politics at Nuffield College, Oxford University, and Senior Fellow of the College. During 2005/6, he served as Acting Warden (2005-06) there. In 2011-12, he served as Senior Proctor of the University) in Bucharest, Romania in 2017 in SCOPE2017 (Science of Politics: 4th International Interdisciplinary Conference of Political Research: Democracy in Development-Comparative Perspectives on the Governance of the Public Good, University of Bucharest, Bucharest, Romania, 26-28 May 2017. http://www.scienceofpolitics.eu accessed June 4, 2017): relying on the idea that the world should be regulated by democratic goals, by a system of justice and social as the rule of law, which should never be devalued by any cultural context or system within political structures and actions. Thus, the vulnerability of the protection, promotion and implementation of the human rights system may be based on democratisation with regard to the quality of democracy. If this is at a low level, certainly the political regime will not be able to reach the basic values and rights to the implementation of an active and protected citizenship. 
Campina, A. \& Silva- Magalhaes, M.M. (2019). Social economy in the international scenery: politic(s), culture(s) and power(s)/pressure(s) manipulation. New Trends and Issues Proceedings on Humanities and Social Sciences. [Online]. 6(3), pp 095-101. Available from: www.prosoc.eu

The present research identified Geopolitics as an actor in the field of international relations, contributing positively or negatively, to democratisation within the policies implemented, debated, protected or violated. At two points, it is possible to identify the following perspectives:

'The physical realities that transcend national and international politics in two frequently overlooked issues with regard to contemporary history concerning world affairs. If geography is evidently the fundamental part, it is also based on the 'why' and the 'what. They may be determining factors, but it is certainly the best concealed' (Marshall, 2016).

'We live in a time when democratic nations are in retreat to the strand of geopolitics, democracy portrays itself. The broader phenomenon is based on the documented 'House of Liberty' that has been marked by declines of freedom in the world, particularly in the last 9 years. On the plane of geopolitics, the movement of tectonic plates produced a systemic effect on the reorganisation of power, but with audible consequences (...)'. Today, as always, democracy is a fragile flower. It requires permanent support, attention and control of the movements and the facing of a 'jungle' that must be seen by its interior (content) and by the outside.

Given the absence of such efforts, the 'jungle' and 'sunflowers' may sooner or later return and claim their land' (Kagan, 2017).

Political scientists do not doubt the importance of Geopolitics, but there are many and many decisions in the field of International Relations and the promotion of human rights policies that do not, or prefer to ignore, the potential of this element that cannot be ignored. But it is easy to see some of the explanations for the success and failure of political, cultural, economic and social measures in an international dimension. For example, in order to protect as many human beings as possible, refugees, especially in Europe, should be treated differently in the geopolitical context, if one were to consider, including diplomatic agreements, the strategy of International Organisations, the humanitarian, solidarity, protection and, in particular, the implementation of human rights legislation in the articulation of the United Nations system, which could prevent millions of deaths and suffering in all dimensions.

Thus, it is already beyond question that there is a change in the human rights paradigm, such as the need for a legal and effective interpretation, for violence and international and national violations, known and unknown by the most indescribable strategies, in perfectly identified needs. There are two different perspectives:

- the need to achieve the implementation of policies that are legally and judicially approved and recognised by (mostly democratic) Governments seeking to protect and promote Human and Fundamental Rights. In this case, the need seeks the development of 'forces' of policies/laws, such as citizenship that denounces violations and violence so often cancelled (deliberately or not).

- the needs of millions of human beings who suffer the most distinct violence and violation of international law, including torture and death. Some are legally protected but do not have effective mechanisms to protect their human rights, much less the possibility of denouncing or questioning such protection. Still others, even living in democratic states, do not experience the values that would be supposed for the most different reasons, which should always be the motivation for a hard work to develop together with political power, a fact that places education at two corners: political and legal changes (hard, complex and often almost utopian missions), such as knowledge of society and its rights (human and fundamental), strategies and their protection and all problems reported.

The well-known need for intervention for democratisation, as far as human values are concerned, aiming at the protection of human beings, aiming at solving bigger problems. It is an effective state of the art in a world society that leaves open difficulties, which need action. 
If international law exists and the international legal framework is structured and has the capacity to carry out an action for the legal protection of citizens. The most serious problem is that it is not applied to the extent of the intervention of international organisations, as well as in the complexity of mutating the rules of non-democratic states, in which the law is 'castrating' and violating those that should be protected Rights, but are effectively violated without (possible) lawsuit (Coutinho \& Ribeiro, 2016).

This must be a mission of and for all, but unfortunately millions of human beings do not have access or sufficient information, which has received no or insufficient education to be protectors, promoters or human rights activists. There are no exceptional movements that trigger active citizenship and responsible human action as mission. This is not a surrealist statement, but only the need to implement international law. This is an integral part of International Relations, developed in different spheres: organisations, states and special movements that can be arranged within the most important values that should support the relations. However, history has shown that human beings have the capacity for a radical change of the best and the worst actors as regard their own protection. In fact, despite all the difficulties and obstacles, Humanity has shown that when there is a true and legitimate desire, with defined strategies, in a junction of needs and the most powerful promoters, it can take time (long or short term) but it is possible achieve different, partial, but positive, results. Action is the 'key'.

\section{Conclusions}

Thinking, reflecting, critically analysing, diagnosing the problems that affect and presenting solutions to everything that involves Human Rights goes far beyond the political, human, cultural or social question, but is based on the legal and judicial structure, at the international and national levels.

If 'corruption is a difficulty combined with the consequences of a certain mentality, cultural policy, geopolitics and economic development', the present scientific investigation allows us to affirm that Education for Human Rights is one of the most important/the development of Democracy in the most different contexts and complex social realities, as well as the change in perception and interpretation of what Human Rights are effectively, the need to denounce and fight against violence, violations and human suffering. This is the mission of all actors in International Relations as a daring and difficult process, whose complexity is 'contaminated' by the most arduous feature: parallel interests and negative manipulations, but no one (individuals, Institutions, Organisations and Governments) can abandon this complex and time-consuming challenge with the aim of overcoming the most diverse obstacles, and it is possible to protect and promote Human Beings.

In fact, if we believe and live democracy, we can understand political power in its responsibilities, but if we are all 'politicians', we have to assume our responsibility as citizens, as humans. Thus, we can conclude that we need to go 'beyond' theories so that Human Rights are a reality lived by as many people as possible.

Finally, the present research allows identifying the problem of legality and social needs, in a dichotomy that contributes negatively to human beings in three dimensions: political, legal and educational. The European Union has all the structures-legal, social, cultural, political and politicalto protect and promote human rights, not only within the European Union and its Member States, but also with regard to International Relations. According to the United Nations system, which is integrated in the philosophy and behaviour of the European Union, despite all the human rights violations it faces, terrorist attacks, violence and discrimination, etc., denounced or not, despite the dangerous information manipulated, consciously or even by 'naive' actions, which justifies the urgent and emergent need to implement an education strategy, preventing the growth of behaviour against these rights and violence, aiming to promote knowledge that allows an understanding and 
interpretation of the competences, developing a true democracy and citizenship, supported unconditionally in Human Rights.

\section{References}

Acemoglu, D. \& Robinson, J. (2013). Why nation fails. Lisboa, Portugal: Temas e Debates.

Campina, A. (2017). Images, international law, political rhetoric and democratic education form Human Right's needs: A study case of Portugal 19332016. New Trends and Issues Proceedings on Humanities and Social Sciences, 4(1), 14-19. https://doi.org/10.18844/prosoc.v4i1.2046

Coutinho, F. \& Ribeiro, M. (2016). Jurisprudencia Resumida do Tribunal Internacional de Justiça (1947-2015). Lisboa, Portugal: Publicacoes Dom Quixote.

Cunha, P. (2003). Direitos Humanos: Teorias e Praticas. Coimbra, Portugal: Almedina.

Fukuyama, F. (1992). O fim da historia e o ultimo homem. Lisboa, Portugal: Gradiva.

Global economic prospects, darkening skies (p. 39). A World Bank Flagship Report. ISSN 1014-8906 2018

Kagan, R. (2017). Is the democracy in decline? The weight of geopolitics. Retrieved from https://www.brookings.edu/articles/is-democracy-in-decline-the-weight-of-geopolitics/

Kelsen, H. (2009). Justica e o Direito Natural. Coimbra, Portugal: Almedina.

Kornelsen, L. (2014). Stories of transformation: memories of a global citizenship practicum. Canada: ICIE.

Maalouf, A. (2009). Identidades Asesinas. Madrid, Spain: Allianza Editorial.

Maquiavel, N. (2015). O Príncipe. Lisboa, Portugal: Bertrand Editora.

Marshall, T. (2016). Prisoners of geography. London, UK: Elliot \& Thomson.

Milanovic, B. (2016). A desigualdade no mundo: uma nova abordagem para a era da globalizacao. Lisboa, Portugal: Conjuntura Atual Editora.

Moury, C. (2016). A democracia na Europa. Lisboa, Portugal: Fundacao Francisco Manuel dos Santos.

OECD. Retrieved from http://www.oecd.org/cfe/leed/social-economy.htm

Public good or private wealth. Oxfam Report, January 2019. Oxford, UK: Oxfam GB. ISBN 978-1-78748-365-1

Radu, M. \& Vegh, Z. (2017). Frontiers of democracy: embebing democratic values in Central and Eastern Europe. Budapest, Hungary: Central European University.

Ramonet, I. (1997). Geopolítica do caos. Rio de Janeiro, Brazil: Editora Vozes.

Rocha, I. (2010). Tratados da Uniao Europeia. Porto, Portugal: Porto Editora.

Sartori, G. (2003). La sociedad multiétnica. Madrid, Spain: Taurus.

SCOPE2017. Retrieved August 10, 2017, from http://www.scienceofpolitics.eu

SCOPE2017. Whitehead. Retrieved August 10, 2017, from http://www.scienceofpolitics.eu/scope-2017/keynoteWhitehead

Smits, J. (2012). Encyclopedia of comparative law, London, UK: Edward Elgar Publishing.

Stephen D. (2018). Lamentavel Mundo Novo. Lisboa, Portugal: Temas e Debates. 